\title{
Activating FLT3 Gene Mutation
}

National Cancer Institute

\section{Source}

National Cancer Institute. Activating FLT3 Gene Mutation. NCI Thesaurus. Code C150623.

A change in the nucleotide sequence of the FLT3 gene that that results in constitutive activation of receptor-type tyrosine-protein kinase FLT3 and its downstream signaling pathways. 